\title{
Развитие российской электронной компонентной базы: взгляд эксперта
}

\author{
А. Щепанов ${ }^{1}$
}

УДК 621.39 | ВАК 05.27.01

\begin{abstract}
В статье проанализированы проблемы импортозамещения электронной компонентной базы (ЭКБ) в высокотехнологичной продукции гражданского и двойного назначения. Андрей Щепанов, начальник управления развития ЭКБ ФГУП "МНИИРИП", основываясь на опыте взаимодействия научной организации с российскими предприятиями-производителями, сформулировал конкретные предложения по ускорению импортозамещения в радиоэлектронной отрасли. С точки зрения специалиста, одним из примеров рационального подхода может служить разработка перспективной космической платформы с использованием модульного принципа построения современных космических аппаратов полностью на отечественной микроэлектронике. Отработка метода будет способствовать развитию радиоэлектронного комплекса страны.
\end{abstract}

гуп «МНИИРИП» - головная научно-исследовательская испытательная организация Минпромторга России в области ЭКБ. Среди задач организации - осуществление научноисследовательской и инженерно-конструкторской деятельности в области развития и применения ЭКБ для обеспечения разработок ВВСТ и продукции общепромышленного назначения.

Сегодня развитие собственной радиоэлектронной промышленности - одна из первостепенных государственных задач. Для обеспечения снижения зависимости отечественных предприятий от импорта и зарубежных технологий Минпромторг России реализует отраслевой план и Государственную программу «Развитие электронной и радиоэлектронной промышленности на 2013-2020 годы».

В соответствии с этими документами перед управлением развития экБ Фгуп "МНИИРИп" Департаментом радиоэлектронной промышленности Минпромторга России поставлены следующие задачи:

- определение текущих потребностей в новых разработках ЭКБ и технологиях для создания современной радиоэлектронной аппаратуры как для силовых ведомств, таки в обеспечение критически важной аппаратуры гражданского

ФГУП «МНИИРИП», начальник управления развития ЭКБ. назначения, таких как связь, телекоммуникации, медицина и других;

- проведение анализа мировых достижений, тенденций развития ЭКБ, материалов и технологий по их созданию, перспективныхтребований к ним как со стороны целевых параметров, так и внешних воздействующих факторов, включая специальные, на основе мониторинга потребностей ведущих организаций-разработчиков современных образцов радиоэлектронной аппаратуры;

- разработка комплексных целевых программ по развитию номенклатуры ЭКБ различного функционального назначения: от микроэлектроники, радиофотоники до пассивной электроники и электротехники, включая перспективные химические источники тока. Оценка выполнения базовых индикаторов государственных, целевых и отраслевых программ развития;

- подготовка технических заданий по созданию электронных компонентов, материалов, применяемых в ЭКБ, а также развитие необходимых технологических работ, контроль за ходом выполнения НИОКР. Проведение мониторинга их внедрения и реализации в конкретные образцы радиоэлектронной аппаратуры.

Анализируя взаимодействие МнИиРИп с российскими компаниями радиоэлектронной отрасли, можно выделить ключевые трудности на пути 

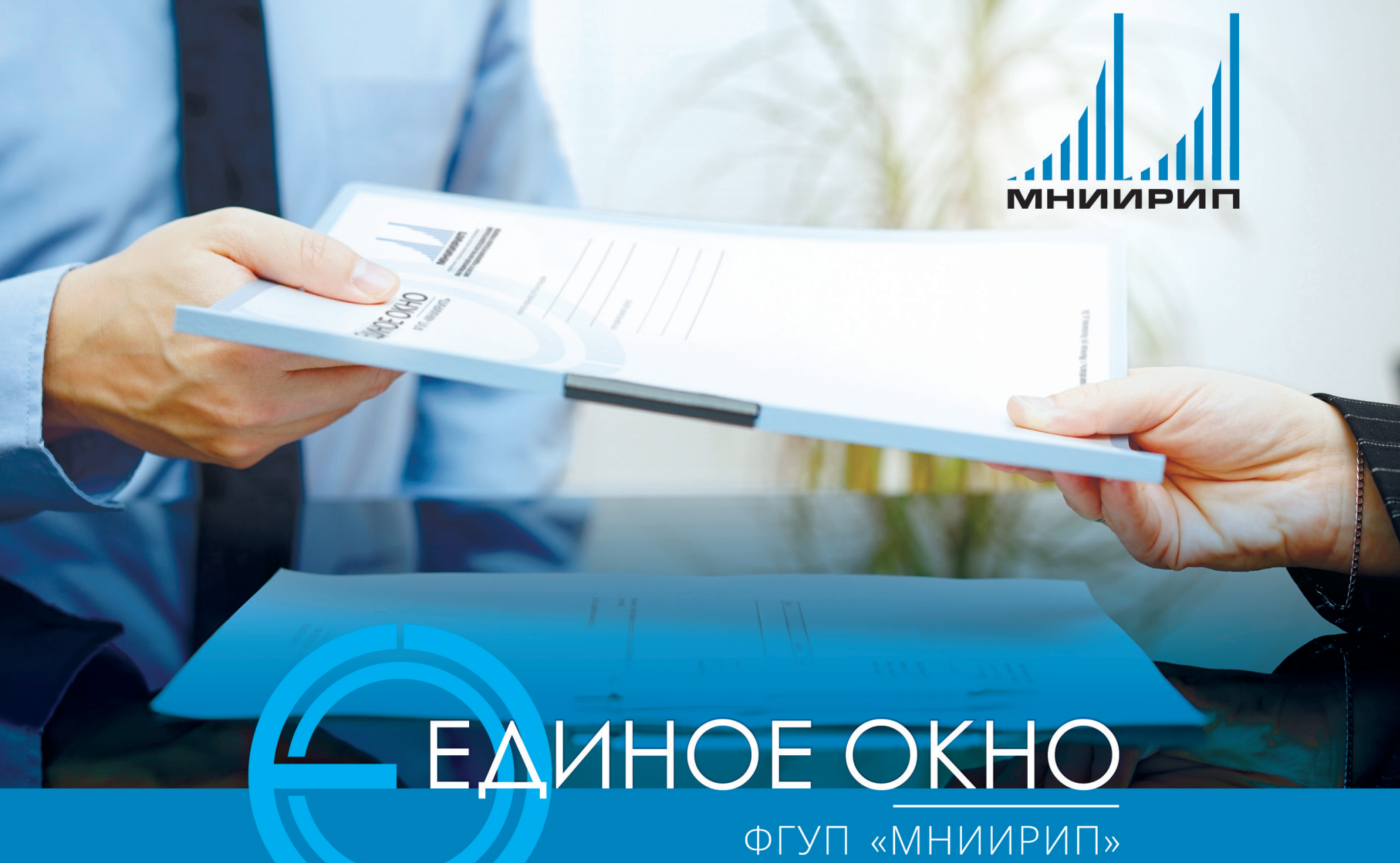

\section{МНОГОФУНКЦИОНАЛЬНЫЙ ЦЕНТР РАДИОЭЛЕКТРОНИКИ - ЕДИНОЕ ОТРАСЛЕВОЕ ИНФОРМАЦИОННОЕ ОКНО}

\section{$\checkmark$ ДОСТУПНОСТЬ, ПРОЗРАЧНОСТЬ И УДОБСТВО ПОЛУЧЕНИЯ УСЛУГ \\ $\checkmark$ ОТСЛЕЖИВАНИЕ СТАТУСА ЗАЯВКИ В ОНЛАЙН-РЕЖИМЕ \\ $\checkmark$ РЕГЛАМЕНТИРОВАННЫЕ СРОКИ \\ $\checkmark$ ЕДИНЫЙ СТАНДАРТ КАЧЕСТВА}

ФГУП «МНИИРИП»

Головная научно-исследовательская организация Минпромторга России в области ЭКБ www.mnitip.ru info@mniirip.ru

Московская область, г. Мытищи, ул. Колпакова, д. 2a 
внедрения импортозамещающей ЭКБ. Основными являются следующие три фактора:

- во-первых, отсутствие требуемых электронных моделей значительной части отечественной номенклатуры ЭКБ, используемой разработчиками аппаратуры в системах автоматизированного проектирования. Это отсутствие четко выявляет другую проблему: необеспеченность отечественными аналогами САПР по проектированию аппаратуры и погруженными в них моделями отечественной ЭКБ:

- во-вторых, необходимость перепроектирования уже разработанной и серийно изготавливаемой аппаратуры под импортозамещающую ЭКБ с последующим проведением типовых испытаний в связи с отсутствием финансирования модернизации и проведения последующих испытаний;

- в-третьих, нет возможности провести закупку отечественной ЭКБ поштучно, а только в минимальном объеме, порой превышающем годовую потребность предприятия-разработчика аппаратуры

Вопросы импортозамещения требуют общесистемных, конкретных мер на межотраслевом уровне. Рассмотрим возможные пути решения перечисленных проблем.

Исходя из анализа практической работы, а также учитывая разработку функциональных отечественных аналогов, не предусматривающих замену pin to pin, наиболее эффективными средствами импортозамещения в радиоэлектронной аппаратуре станут комплексные, схемотехнические методы ее переработки на основе созданного минимального функционального набора отечественной ЭКБ. Поэлементная замена компонентов иностранного производства на отечественные показала свою неэффективность, выраженную в перепроектировании и перетрассировке электронных плат с изменением питающих напряжений и управляющих токов, а также в последующем проведении полного набора предусмотренных испытаний.

Одним из примеров импортозамещения ЭКБ может служить разработка перспективной космической платформы с использованием модульного принципа построения современных космических аппаратов полностью на отечественной микроэлектронике.

Соответственно, импортозамещение ЭКБ возможно и необходимо проводить только комплексно, а не по точечному принципу замены одного компонента на другой.

Среди принятых мер хочу отметить создание электронной торговой площадки «ЭКБ МАРКЕТ».
Актуальный инструмент призван снять большую часть проблемных вопросов предприятий отрасли на пути импортозамещения электронных компонентов.

В этой связи сконцентрирую внимание на источниках, которые помогают найти внутренние ресурсы для снижения импортозависимости в радиоэлектронной промышленности

Главный скрытый резерв - это преобразование отрасли из обеспечивающей в формирующую в условиях активного роста новых рынков, основанных на технических решениях радиоэлектронной промышленности.

Предприятиям нужно ориентироваться на создание конечных продуктов, включающих в себя аппаратно-программную часть и сервисы, генерировать инновационные решения в импортоопережении, а не импортозамещении

При этом важным аспектом была и остается оптимизация себестоимости продукции под требования конечных потребителей, ее адаптация к условиям рынка. Необходимо максимально использовать имеющийся и создаваемый потенциал отрасли для сокращения затрат при решении повторяющихся, по сути, задач: САПР, ІР-блоки, ЭКБ.

Вместе с тем таможенное регулирование импорта продукции радиоэлектронной промышленности. Здесь необходимо обратиться к зарубежному опыту. Например, защита внутренних рынков Китая от импорта и конкуренции включает в себя высокие тарифы, нетарифные барьеры и другие регуляторные препятствия. Аналогичные меры необходимо использовать и в России.

Экспортная ориентированность - фундаментальное правило для развития отрасли в условиях конкуренции и невозможности избежать включенности в процессы глобального разделения труда. Необходимо делать ставку на креативный потенциал России: сложные нестандартные продукты, включая высокотехнологичную безопасность, уникальные решения, используемые в сложных, непредсказуемых сферах и зонах, таких как атомная промышленность, космос, Арктика, океан.

Анализ стратегии необходимо подкреплять конкретикой, поэтому стоит сказать о практических результатах работы управления развития ЭКБ ФгУп "Мниирип" за период 2018-2019 годов.

Совместно с предприятиями радиоэлектронной аппаратуры мы разработали основные направления развития ЭКБ в период до 2030 года. На этой базе создан и проходит согласование проект комплексной целевой программы «Развитие микроэлектроники». 
Цель - к 2027 году достичь максимальной технологической независимости в области технологий, материалов, полуфабрикатов, программного обеспечения.

Реализуется программа импортозамещения ЭКБ изготовленной в странах альянса НАTO и ЕС, а это более 300 ОКР по разработке свыше 1,5 тыс. типов изделий ЭКБ, призванных функционально заместить более 7 тыс. типов иностранной ЭКБ

Создаются комплексы документов по стандартизации разработки, проведению испытаний и серийного изготовления ЭКБ, предусматривающие новые функциональные группы изделий ЭКБ, ВКлючая ІР-блоки, электронные модели функционирования как двойного, так и гражданского назначения

Ведется работа по классификации материалов, применяемых при создании и изготовлении ЭКБ

Успешность реализации проектов Минпромторга россии по отраслевым планам во многом зависит от взаимодействия нашей научной организации с предприятиями отрасли

\section{Каких практических результатов удалось достичь управлению по развитию ЭКБ?}

В 2018 году во ФГУП «МНИИРИП» был разработан алгоритм анализа уровня обеспеченности и применяемости в образцах радиоэлектронной аппаратуры отечественной ЭКБ и проведена оценка зависимости от применения компонентной базы иностранного производства при разработке и производстве более 100 образцов аппаратуры.

Осуществленный по данной методике анализ позволяет провести оценку степени реальной зависимости от использования иностранных изделий при разработке, производстве и сервисном обслуживании образцов аппаратуры с заданной степенью детализации по различным областям применения ЭКБ. Инструмент дает возможность определить состояние выполнения предприятиями отрасли мероприятий по импортозамещению и повышению технологической независимости.

В настоящее время налажена системная работа в части анализа и снижения импортозависимости с госкорпорациями "Ростех" и "Роскосмос", организовано взаимодействие с различными федеральными органами исполнительной власти и силовыми структурами.

Совершенствование механизмов взаимодействия с предприятиями-разработчиками и потребителями отечественной эКБ - важное направление, которое МнИИРИп развивает как единый отраслевой центр радиоэлектроники.
Для реализации этих принципов в нашем научном институте идет работа по созданию приемной в формате единого окна. Фокус новой концепции направлен на обеспечение оперативности, прозрачности процедур и работ, осуществляемых предприятиями отечественной промышленности во взаимодействии с МНИИРИП, Минпромторгом России, другими задействованными организациями и отраслевыми институтами.

Так, например, в системе "единое окно" для согласования технического задания на ОКР по созданию ЭКБ будет обеспечено рассмотрение и согласование проекта как с МНИИРИП, Минпромторгом России, так и с Филиалом 46 ЦнИИ Минобороны России в рамках одной процедуры. Посредством внедряемой услуги уполномоченному представителю предприятия достаточно представить заявление, проект технического задания и в строго регламентированные сроки получить документы с результатами согласований.

Проект услуги "единое окно» был представлен к обсуждению на III научно-практической конференции, проведенной ФГУП «МНИИРИП» в мае 2019 года и собравшей более 300 представителей отрасли.

Конференция позволила получить обратную связь от потенциальных потребителей услуг в формате единого окна. Для детального обсуждения технических и процедурных вопросов внедрения нового механизма взаимодействия была проведена серия круглых столов. Активное участие в наших мероприятиях представителей промышленности подтверждает высокий интерес к разрабатываемому проекту и своевременность его внедрения.

В результате МнИИРИП должен стать для предприятий радиоэлектронной промышленности отраслевым центром компетенций, который сможет решать их проблемы в короткие сроки и без бюрократических проволочек.

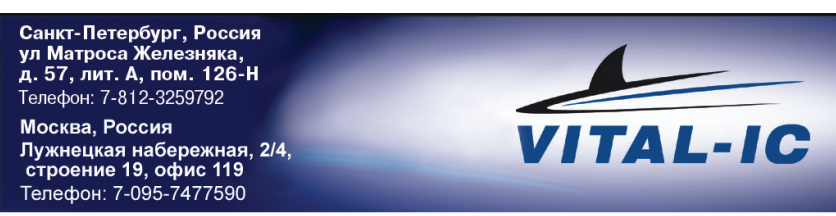

Поставки электронных компонентов

широкой номенклатуры

Системы RFID: поставка и консультации

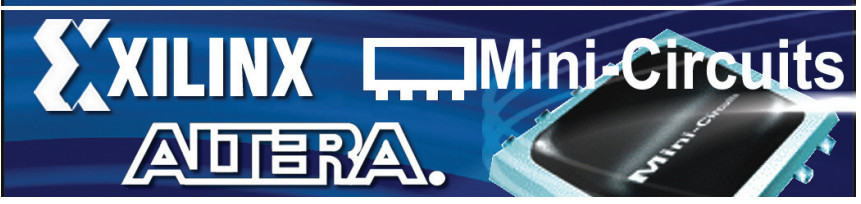

